\title{
Social Capital in WeChat: Moderating Role in Anxiety and Relationship with Use Intensity
}

\author{
Jiaqi Li \\ Vanke Meisha Academy, Shenzhen 518000, China \\ *Corresponding Author email: info@tet100.com
}

Keywords: social; capital; anxiety

\begin{abstract}
Based on these findings, this paper tries to learn how social capital mediate the relationship between WeChat use intensity which may positively correlate with anxiety and anxiety level. This paper controlled anxiety level and bridged social capital for the regression analysis for WeChat use intensity and bonding social capital, and for regression analysis of WeChat use intensity and bridging capital is bonding social capital. It can be found that the interaction between anxiety measures and bonding social capital, and anxiety measure itself predicted WeChat use intensity. With bonding social capital multiplying anxiety measure, WeChat usage intensity is affected positively. The presence of bonding social capital mediates the negative relationship between anxiety and WeChat intensity, suggesting its positive association with WeChat intensity or its role in reducing measure anxiety level.
\end{abstract}

\section{Introduction}

As the first social media whose amount of users surpass 1 billion in China, Wechat plays a vital role in daily communicating and building interpersonal relationship. According to China Social Media Impact Report 2017 made by Kantar, one of the world's largest consultancy group, Wechat's satisfactory rating is the highest among all other social media in China including Weibo, which is the Chinese equivalent Twitter (Kantar, 2017).

Wechat enables users to text messages, which is essential service of all social media, to friends and allows users to post text and images, share music and share articles in a platform "moment" which only opens to user's friends. Adding friends can be achieved through a variety of ways such as searching email or phone number and a function named "people nearby," detecting adjacent Wechat users.

Early research suggests that social media is used by netizens to develop online to offline connections, relating to new friends who share common interests with users (Wellman, Salaff, Dimitrova, Garton, Gulia, \& Haythornthwaite, 1996). However, maintaining pre-existing relationships can still be a vital purpose that leads to the usage of social media. In fact, the two primary motivations of using Wechat is "knowing what's going on with friends" and "communicating with friends and family members" (Kantar, 2017), both inferring to acquaintance-social. Such a pattern of usage of Wechat provides insight for researchers to explore the interaction between social capital and Wechat usage. Research indicates that Facebook, one of the most popular social network sites in the U.S., is related to attitudes and behaviors that enhance individuals' social capital (Valenzuela, Park, \& Kee, 2010). Nevertheless, limited number of researches of social capital has been done on Wechat.

This study uses Wechat as a research context to investigate the relationship between social media and offline social capital and social capital's role in affecting anxiety, specifically targets high school students aged 15-19 since their prevalence of anxiety disorder is the highest (National Institute of Mental Health, 2004), and usage of social media is at high frequency. 


\section{Literature Review}

\subsection{Social Capital}

Generally, social capital refers to accumulative network resources involved in groups or interpersonal relationships. Understood roughly as the goodwill that is engendered by the fabric of social relations and that can be mobilized to facilitate action (Adler, P. S., \& Kwon, S. W., 2002). In this context, goodness doesn't mean virtue but sympathy, trust, and forgiveness offered us by friends and acquaintances (Hughes, H. P., 1982).

Social capital's denotation has various explanations depending on the different field of research. Confusion mainly pertains to whether social capital is cause or effect. Foley and Edwards (1997) consider that social capital is the positive effect created by social groups. However, some researchers argue that social capital can be both cause and effect as Putnam suggests that social capital is social networks and their associated norms of reciprocity (Putnam, 2000). The concept of social capital embraces all the social collective, economic and cultural resources to which a community has access (Pilkington, P., 2002). Generally, social capital refers to accumulative network resources involved in groups or interpersonal relationships.

Under the big umbrella of social capital is bridging social capital and bonding social capital (Williams, 2006), differing in the strength of connection and time length which the relationship lasts. Bridging social capital refers to weak connections between individuals who may provide new perspectives and information for each other but not emotional support (Granovetter, 1982). From another perspective, bonding, or integrating, relationships take place within the group and facilitate interaction and collective action within it. Bridging, or linking, relationships strengthen linkages between the group and other organizations (Grootaert, C., \& Bastelaer, T. V., 2001).

In 2011, among the limited number of studies on social media and its impact on social capital in China, research found that the use intensity of Renren, which is a now out-of-date social media designed for college students, is positively related to perceived social capital (Zheng, P., \& Wang, H., 2011). However, the population in this study was Chinese college students, and bonding social capital and bridging capital was not measured separately.

Social media's characteristic, which allows users to share their thoughts on an open platform, meet new friends and, provides users with opportunities to maintain large diffuse ties (Wellman et al., 2001), is a hue of its effect of accumulating bridging social capital. Indeed, relationship maintenance behaviors on Facebook, such as congratulation and sympathizing with others lead to increased bridging social capital (Ellison, N. B., Steinfield, C., \& Lampe, C., 2007). As such, we propose first hypothesis:

H1: Intensity of Wechat use will be positively associated with individuals’ perceived bridging social capital.

As Erikson (2011) put that close relationships are criteria for "friending" someone, social media also serves to maintain preexisting relationships. In fact, in one study, Facebook is utilized much more significantly in the maintenance of pre-existing social capital instead of the formation of new social capital or other motivations (Suek, E., Neubauer, A., Collins, A., Anderson, A., \& Hayes, Z., 2009). So we propose the second hypothesis:

H2: Intensity of Wechat use will be positively associated with individuals' perceived bonding social capital.

\subsection{Anxiety}

Recently, more and more studies suggest that social media negatively impact users' psychological health such as anxiety induced by pictures of celebrities who have athletic body figure (Dittmar, H., \& Howard, S., 2004). Nevertheless, bonding and bridging social capital that social media helps to form may reduce anxiety level as Lee (2013) indicates that both bonding social capital and bridging social capital reported by respondents appeared to be greatest under conditions of low anxiety attachment. And for students with lower attachment anxiety, the relationships between intensity of social network 
site use and bonding and bridging social capital were stronger than those with higher attachment anxiety (Liu, H., Shi, J., Liu, Y., \& Sheng, Z., 2013). After March 2011 meltdowns at the Fukushima nuclear power plants in Japan, local residents were under great risk of psychological disorder. Researchers in Japan found out that having high levels of social capital plays an important role in reducing anxiety and distress among Futaba residents (Iwasaki, K., Sawada, Y., \& Aldrich, D. P., 2017). Based on these findings, we want to learn how social capital mediate the relationship between Wechat use intensity which may positively correlate with anxiety and anxiety level. Thus, we propose hypotheses 3 and 4.

H3: The relationship between intensity of Wechat use and anxiety level will vary depending on the bridging social capital.

H4: The relationship between intensity of Wechat use and anxiety level will vary depending on the bonding social capital.

\section{Method}

Subjects are randomly selected from high schools which located in major cities in China. An online survey that evaluates individual Wechat usage intensity, anxiety level, bridging social capital and bonding social capital is distributed out through online platform Wenjuan (wenjuan.com) to Wechat. 135 high school students finished the survey without compensation, yielding 31\% response rate. The summary statistics below shows that the average age of participants is 16.99 years old. Female subjects consist of $67.4 \%$ of all participants, and $64 \%$ of participants live on campus, both may lead to overrepresentation bias in this study.

Table 1 Sample demographics $(\mathrm{N}=135)$

$\begin{array}{lcc}\text { Gender: } & \text { Mean } & \text { S.D. } \\ \text { male } & 33 \%(44) & \\ \text { female } & 67 \%(91) & 1.02 \\ \text { Age } & 16.99 & 0.76 \\ \text { Year in school } & 2.13 & \\ \text { Residence: } & & \\ \text { on campus } & 64 \%(87) & \\ \text { Off campus } & 36 \%(48) & \end{array}$

\section{Analysis}

To investigate our hypotheses that the relationship between the intensity of Wechat use, and individuals' perceived bridging social capital and bonding social capital, linear regression analysis was adopted. We controlled for anxiety level and bridging social capital for the regression analysis for Wechat use intensity and bonding social capital, and for regression analysis of Wechat use intensity and bridging capital is bonding social capital. The unstandardized coefficient of the relationship between Wechat use intensity and bonding social capital is 0.304 which is positive, indicating those two variables are moderately positive associated, and the p-value 0.003 signals that the relationship is statistically significant which supports hypothesis 1 . Similarly, bridging social capital was found a statistically significant moderate positive association, slightly stronger than the one between bonding social capital and Wechat use intensity, with Wechat use intensity which supports hypothesis 2 $(\mathrm{B}=0.463 ; \mathrm{p}<0.001)$. 
Table 2 Regressions predicting the amount of Wechat intensity from bonding and bridging social capital variables

DV: Wechat use intensity

\begin{tabular}{r|cc}
\hline & $\mathrm{B}$ & $\mathrm{P}$ \\
IV: bonding social capital & 0.304 & $*$ \\
IV: bridging social capital & 0.463 & $* *$ \\
$1 * \mathrm{p}<.01, * * \mathrm{p}<.001$ & &
\end{tabular}

To test hypothesis 3, we examined the interaction between bridging social capital and anxiety level. As table 3 shown below, Wechat use intensity was statistically significant predicted by anxiety level $(\mathrm{B}=-1.371 ; \mathrm{p}<.001)$ and the interaction between Wechat intensity and anxiety level $(\mathrm{B}=.047 ; \mathrm{p}<.001)$ that supports the relationship between the intensity of Wechat use and anxiety level will vary depending on the bridging social capital. De facto, the presence of bridging social capital ameliorates the negative association between anxiety and Wechat intensity which the level of Wechat usage decrease with the increase of anxiety as observed from respective unstandardized coefficients (B).

Table 3 Interaction of Wechat intensity and anxiety on bridging social capital

$\begin{array}{ccc} & \text { DV: Wechat use intensity } & \\ \text { anxiety } & \mathrm{B} & \mathrm{p} \\ \text { anxiety*bridging social } & -1.371 & * * \\ \text { capital } & .047 & * * \\ 1 * \mathrm{p}<.01,{ }^{* *} \mathrm{p}<.001 & & \end{array}$

To explore hypothesis 4, the interaction between bonding social capital and anxiety level was examined. Table 4 shows that Wechat intensity is significantly predicted by anxiety $(\mathrm{B}=-.779 ; \mathrm{p}<.01)$ and the interaction between bonding social capital and anxiety level $(\mathrm{B}=.035 ; \mathrm{p}<.01)$ that supports the relationship between intensity of Wechat use and anxiety level will vary depending on the bonding social capital. Likewise, the presence of bonding social capital mitigates the negative association between anxiety and Wechat intensity.

Table 4

$\begin{array}{ccc} & \text { DV:Wechat use intensity } & \\ & \mathrm{B} & \mathrm{P} \\ \text { anxiety } & -.779 & * \\ \text { Anxiety*bonding social } \\ \text { capital } \\ 1 * \mathrm{p}<.01\end{array}$

\section{Discussion}

To date, social capital which formed online, especially popular social media in China such as Wechat and Weibo, hasn't received much attention. Due to the difference between social media and the culture that involved in it, research result from Facebook or Twitter cannot be applied directly to others. This study aims to investigate social capital formed on Chinese social media, providing insight for researchers about the situation in China.

Our first two hypotheses' results which explore the role that played by social media in affecting social capital indicates that social media do serve to affect the accumulation of social capital. In particular, both bridging and bonding social capital are positively associated with the intensity of Wechat usage. As mentioned before in literature review, bonding social capital is a strong tie that facilitates interaction and action within groups, typically involved emotional support (Ellison, N. B., 
Steinfield, C., \& Lampe, C., 2007). Earlier study has suggested that connections on social media are new, inferring bonding social capital rarely can be influenced by social media. However, our study shows that social media, in fact, is related to bonding social capital, old existing relationships, which negate that statement's validity in Wechat's case. Bridging social capital is positively associated with Wechat usage which may indicate that Wechat served as a platform for initiating new connections, lower the traditional barrier for building interpersonal including face to face conversation and even provide social anxiety disorder patients with a better way to socialize.

Additionally, we found that the interaction between anxiety measures and bonding social capital, and anxiety measure itself predicted Wechat use intensity. Anxiety measure affects Wechat usage intensity negatively. However, with bonding social capital multiplying anxiety measure, Wechat usage intensity is affected positively. The presence of bonding social capital mediates the negative relationship between anxiety and Wechat intensity, suggesting its positive association with Wechat intensity or its role in reducing measure anxiety level. If further research proves possible that social capital indeed reduces anxiety significantly, Psychologist may adopt increasing social capital as a strategy to treat anxiety disorder or prevent from getting any psychological disorder.

Limitations in this study include the fact that this study only focuses on high-school students using Wechat, so the relationship between Wechat intensity, social capital and anxiety cannot be generalized to other groups such as dropped out teenagers or young adults. Besides, this study adopted GAD-7 (General Anxiety Disorder-7) which is a self-report to measure the severity of general anxiety. Consequently, subjects may overestimate their level of general anxiety because of social desirability (Tanaka-Matsumi, J., \& Kameoka, V. A. 1986). Finally, female respondents who use social media more frequently than male (Perrin, A. 2015) are slightly overrepresented in the sample, which may result in higher Wechat usage intensity.

\section{Conclusion}

In this study, we predict the direction in which Wechat usage intensity influence social capital and the effect of social capital on affecting the relationship of Wechat intensity and anxiety. The result shows that Wechat usage contributes to accumulate both bonding social capital, which is a strong tie that provides individual emotional support, and bridging social capital that provides new perspective for people. Accordingly, Wechat is not just a platform where to socialize with new friends, but also to maintain and strengthen relationships with the acquaintance. Moreover, Wechat can be adopted as a new method to increase the social capital of communities such as companies which require strong bonding to improve corporation and work efficiency. From the regression analysis of the interaction of social capital and anxiety and anxiety itself, we learn social capital's mediating role in anxiety level, providing a new solution of prevention and treatment in general anxiety for Psychologist.

\section{References}

[1] Adler, P. S., \& Kwon, S. W. (2002). Social capital: Prospects for a new concept. Academy of management review, 27(1), 17-40.

[2] Dittmar, H., \& Howard, S. (2004). Thin-ideal internalization and social comparison tendency as moderators of media models' impact on women's body-focused anxiety. Journal of Social \& Clinical Psychology, 23(6), 768-791.

[3] Ellison, N. B., Steinfield, C., \& Lampe, C. (2007). The benefits of Facebook "friends:" Social capital and college students' use of online social network sites. Journal of Computer-Mediated Communication, 12(4), 1143-1168.

[4] Ellison, N. B., Vitak, J., Gray, R., \& Lampe, C. (2014). Cultivating social resources on social network sites: facebook relationship maintenance behaviors and their role in social capital processes. Journal of Computer-mediated Communication, 19(4), 855-870. 
[5] Foley, M. W., \& Edwards, B. (1997). Escape from politics? Social theory and the social capital debate. American Behavioral Scientist, 40(5), 550-561.

[6] Granovetter, M. S. (1982). The strength of weak ties: A network theory revisited. In P. V. Mardsen \& N. Lin (Eds.), Social Structure and Network Analysis (pp. 105-130).

[7] Grootaert, C., \& Bastelaer, T. V. (2001). Understanding and measuring social capital: a synthesis of findings and recommendations from the social capital initiative. Earth Surface Processes \& Landforms the Journal of the British Geomorphological Research Group, 30(7), págs. 901-912.

[8] Iwasaki, K., Sawada, Y., \& Aldrich, D. P. (2017). Social capital as a shield against anxiety among displaced residents from fukushima. Natural Hazards, 89(1), 405-421.

[9] Pilkington, P. (2002). Social capital and health: measuring and understanding social capital at a local level could help to tackle health inequalities more effectively. Journal of Public Health, 24(3), 156-159.

[10] Suek, E., Neubauer, A., Collins, A., Anderson, A., \& Hayes, Z. (2009). Facebook and the maintenance of social capital. Journal of Materials Science, 31(16), 4221-4226.

[11] Tanaka-Matsumi, J., \& Kameoka, V. A. (1986). Reliabilities and concurrent validities of popular self-report measures of depression, anxiety, and social desirability. Journal of Consulting \& Clinical Psychology, 54(3), 328-33.

[12] Wellman, B., Salaff, J., Dimitrova, D., Garton, L., Gulia, M., \& Haythornthwaite, C. (1996). Computer networks as social networks: collaborative work, telework, and virtual community. Knowledge \& Communities, 22(22), 213-238.

[13] Valenzuela, S., Park, N., \& Kee, K. F. (2010). Is there social capital in a social network site?: facebook use and college students' life satisfaction, trust, and participation1. Journal of Computer-mediated Communication, 14(4), 875-901. 